\title{
Ascertaining the Financial Cost of Malaria and Mitigating against It Using Actuarial Models for Financial Cost
}

\author{
I. K. Dontwi ${ }^{1}$, V. K. Dedu ${ }^{1} \&$ N. K. Aboagye ${ }^{1}$ \\ ${ }^{1}$ Department of Mathematics, Kwame Nkrumah University of Science and Technology, Kumasi, Ghana \\ Correspondence: Vincent Kofi Dedu, Department of Mathematics, Kwame Nkrumah University of Science and \\ Technology, University Post Office Box 5 KNUST, Kumasi, Ghana. Tel: 233-20-050-1355. E-mail: \\ vkdedu.cos@knust.edu.gh, vincentdedu@hotmail.com
}

Received: January 26, 2013

Accepted: June 14, $2013 \quad$ Online Published: June 24, 2013

doi:10.5430/ijfr.v4n3p94

URL: http://dx.doi.org/10.5430/ijfr.v4n3p94

\begin{abstract}
The cost of malaria treatment is crippling Ghana's health budget. Malaria slows down economic growth and if not checked, it can erode the National Health Insurance Fund (NHIF). The cost of treating malaria in 2008 was US $\$ 772.4$ million. This amount is equal to Ghana's entire health budget for 2008 , which represents $10 \%$ of the country's entire Gross Domestic Product for 2006 (MOH Report - Quashigah, 2008).

The financial cost of malaria treatment and its cost mitigation in Ghana is determined using actuarial models and a health scheme which also mitigates the cost of malaria is postulated. The KNUST hospital is the case study for obtaining the treatment cost of malaria. This study involves estimates of morbidity and mortality rates for malaria. Furthermore, a premium formula is developed using the cost data obtained from the hospital and the premium formula. Premium rates are calculated for the different scheme members, based on some predetermined factors. Ultimately recommendations have been made about how this proposed scheme can be incorporated into the current National Health Insurance Scheme (NHIS).
\end{abstract}

Keywords: mortality, morbidity, survival rate, actuarial present value, equivalence principle, financial cost

\section{Introduction}

Malaria contributes significantly to the poor health and economic conditions in Africa. It is on record that Sub-Saharan Africa (SSA) accounts for $90 \%$ of all malaria cases and deaths worldwide. The effect of malaria is especially more pronounced among children and pregnant women because they have less immunity to the disease. Malaria is both a disease of poverty and a cause of poverty. Not only are poor people at an increased risk of malaria infection and death, but also they are less likely to be in a position to pay either for effective malaria treatment or for transportation to a health facility capable of treating the disease (Akazili, 2002). Thus an investigation into schemes to mitigate the financial burden of malaria on the affected persons. In Ghana, most government projects are geared towards reduction in the number of malaria cases: embarking on joint efforts with AngloGold Ashanti (AGA), Presidential Malaria Initiative (PMI), and Global Fund for indoor residual spraying (IRS) in some selected districts in Ghana (PMI e- newsletter, 2010). But no unique scheme exists to cater for the infected and their financial expenditures.

\subsection{Objectives of the Study}

The study will:

I. Estimate the economic and financial cost of malaria. The Kwame Nkrumah University of Science and Technology (KNUST) hospital will be the case study.

II. Estimate mortality and morbidity rates for malaria. The population will be divided into three sub-populations;
(a) Under-5 year olds
(b) Pregnant women
(c) Everyone else, specifically, non-pregnant adults 
The reason for this distinction is that, in general, very young children and pregnant women are the population group at highest risk with respect to malaria morbidity and mortality because they have a lower and lowered immunity respectively. Most children experience their first malaria infections during their first five years because they have not yet acquired adequate clinical immunity. Adult women have a level of immunity but this is impaired during pregnancy (Adams et al, 2004).

III. Calculate premium rates for such a Malaria Health Insurance.

IV. Make recommendations on how this scheme can be modified to fit into the National Health Insurance Scheme (NHIS).

\subsection{Problem Statement and Significance of Study}

Malaria is a one of the major killer in Ghana. It is hyper-endemic in Ghana and is the number one cause of morbidity accounting for over $40 \%$ of outpatient attendance in public health facilities with annual reported cases of about 2.2 million between 1995 and 2001 (Centre for Health Information Management, Ghana Health Service, 2003).

Its effects on the national GDP cannot be over-emphasized. Currently, there exists no health scheme catering uniquely for the financial and economic ravages of malaria in Ghana. The results of this study can be used to set up a comprehensive Health scheme to mitigate the financial burden of malaria. A routine finance structure (such as a monthly premium or annual tax) can be developed by Government, ensuring that money is available to pay for the healthcare cost of malaria. The mortality and morbidity rates estimated can also be used for demographic and socio-economic planning by Government.

\subsection{Limitations of the Study}

The data source for this study was limited to information obtained from the KNUST hospital. Malaria charges at the hospital might not be representative of the general cost associated with malaria throughout the country and this might distort our estimates of the cost of malaria and ultimately affect our premium calculation.

In order to construct a morbidity and mortality table for malaria in Ghana, we need records on reported incidences of malaria and the effects of these occurrences. Data regarding the incidence of malaria in Ghana compiled by the WHO is only up to 2008 (WHO world malaria report, 2009) and hence we have to project cases for the years 2009, 2010, 2011, 2012 and 2013. These projections might deviate drastically from reality and hence give unrealistic or impractical results which will inadvertently distort our premium calculations. Furthermore data from the WHO excluded information on the cases regarding pregnant women and hence this had to be estimated subjectively from the available data.

There are currently a lot of government projects and initiatives concerning malaria. These projects will likely reduce the morbidity and mortality rates of malaria. Also there is a general improvement in the effectiveness of the primary Health Care system in Ghana and this will cause a decline in morbidity and mortality rates of malaria over time.

However, empirical studies also show that the malaria parasite tends to develop resistance against some of the anti-malarial drugs and this tends to increase the morbidity rates of malaria over time. Furthermore, the burden of malaria is increasing over time, and this may be the result of several factors, including poor living conditions, association between malaria and HIV/AIDS, climate and environmental change, and inadequate interventions and control strategies. The above listed factors make it extremely difficult to project the trend in malaria morbidity and mortality and its effects over a long period of time. This is because as one set of factors improves the morbidity and mortality rates, the other set of factors worsen the rates.

Due to the above listed limitations, the coverage period shall be restricted to three years and hence we shall be modeling a 3-year term health insurance. Any coverage period longer than this will result in inaccurate projections.

\section{Methodology}

The insurance scheme shall provide three main health covers, depending on the severity or intensity of the infection. The first type will cover the cost associated with a normal malaria infection or episode. This includes the cost of consultation, testing, treatment and medication and possibly transportation to the health facility. The second type will cover the cost incurred when the infection is so severe that it requires hospitalization or admission. This will usually include the above mentioned costs, as well as charges for staying at the hospital and extra charges for medications not included above like injections, being on drip etc. The final type will cover the cost associated with death from a malaria infection. This will include the above mentioned hospital expenses and funeral expenses. Since funeral expenses vary greatly and is dependent on a myriad of factors such as family status in society, number of persons attending funeral, venue, period of funeral, morgue charges etc, we shall treat the death benefit as one similar to that 
of a life insurance. That is, the policyholder will choose a benefit amount to be paid upon death from malaria and hence premiums will vary accordingly, unlike the premiums for normal and severe cover which are fixed amounts.

The following information was obtained from the KNUST hospital vis-à-vis cost of malaria.

Table 1. Summary of the average costs associated with a malaria episode at KNUST Hospital

\begin{tabular}{lcc}
\hline COST ITEM & AMOUNT IN GH $\notin$ \\
\hline Lab Work (malaria test) & 5 \\
Consultancy & & 10 \\
Drugs and medication & & depends on severity of infection \\
Bed (per day) & & 12 \\
Ambulance (to and fro) & KATH & 40 \\
& SMS & 50 \\
\hline
\end{tabular}

And as per the definition of the three types of covers, the following information can be extracted.

Table 2. Summary of costs (benefit amounts) associated with each cover type

\begin{tabular}{llc}
\hline TYPE OF COVER & COST ITEMS & $\begin{array}{c}\text { AMOUNT IN } \\
\text { GH cedis }\end{array}$ \\
\hline First Type (out-patient cover) & $\begin{array}{l}\text { Lab work, consultancy, drugs } \\
\text { and medication. }\end{array}$ & 23 \\
Second Type (Severe cover) & $\begin{array}{l}\text { Same as out-patient cover plus } \\
\text { cost of admission and more } \\
\text { expensive medication and } \\
\text { transportation cost. }\end{array}$ & 107 \\
Third Type (comprehensive cover) & $\begin{array}{l}\text { Same as severe plus death } \\
\text { benefit }\end{array}$ & $107+\mathrm{D}$ \\
\hline
\end{tabular}

Assumptions

- Drug and medication for outpatient was assumed to be GH 8.

- Drug and medication for severe was assumed to be GH 12.

- Drug and medication for comprehensive was assumed to be $\mathrm{GH}$ 12.

- D represents the death benefit chosen by the insured.

We assume that the information presented in Tables 1 and 2 are representative of the national average cost of malaria in Ghana.

\subsection{Estimating Morbidity and Mortality Rates for Malaria}

We make the following assumptions before we proceed:

a) An individual can get at most one episode of malaria in a year. This assumption, though simplistic, is very realistic because most malaria infections or episodes actually occur during the rainy season which happens once a year.

b) Uniform Distribution of Infection (UDI). This is essentially saying that the rate of infection is uniform during the year. This is a very convenient, though unrealistic, assumption. In reality, the probability of getting infected during the year is not uniform and depends on the time of the year with a peak in infections during the rainy season.

Although a lot is advertised about the rampaging negative effect of malaria on pregnant women, data only exists for children and adults. That is, under-5 year olds and over-5 year olds. There is no distinction in the adult's cases for pregnant women and others. For our study, we will assume that pregnant women have a $50 \%$ higher chance of 
getting infected with malaria than other adults. Although this is a subjective assumption, it mimics reality because according to the WHO, pregnant women are more likely to get infected from the malaria parasite with a probability between $30-70 \% .50 \%$ was chosen since it is the mid-point probability.

Denoting the total number of adult infections by $\mathrm{N}$ and non-pregnant adult infections by $\mathrm{n}_{1}$, we obtain the following equations:

Total number of adults,

$$
\begin{gathered}
\mathrm{N}=\mathrm{n}_{1}+\mathrm{n}_{2} \\
\mathrm{~N}=\mathrm{n}_{1}+1.5 \mathrm{n}_{1} \\
\mathrm{~N}=2.5 \mathrm{n}_{1}
\end{gathered}
$$

where $\mathrm{n}_{2}=1.5 \mathrm{n}_{1}$ is the number of infected pregnant women using the above assumption.

We can simplify to get

$$
\mathrm{n}_{2}=\mathrm{kN}
$$

Where

$$
\mathrm{k}=\frac{1.5}{2.5}=0.6
$$

\subsection{Estimating Morbidity and Mortality Rates}

Morbidity and mortality rates will be estimated using the number of malaria infections, admissions and deaths, and Ghana's population size. Data for the malaria numbers (infections, admissions and deaths) were obtained from the WHO's 2009 world malaria report and the population data was obtained from the Ghana Statistical Service. Noting that we are currently in the year 2010 and the malaria data ends in the year 2008 and similarly, the population data ends in the year 2000, we need to utilize statistical techniques in order to estimate or predict values for 2010 and beyond. We begin this by plotting scatter plots to check for patterns or relationships between the years and the reported malaria cases.

Table 3. Number of reported malaria cases in Ghana (infections)

\begin{tabular}{ccccccc}
\hline Year & $\begin{array}{l}\text { Reported } \\
\text { Malaria } \\
\text { cases, all } \\
\text { ages }\end{array}$ & $\begin{array}{l}\text { Reported } \\
\text { Malaria } \\
\text { cases, }<\mathbf{5}\end{array}$ & $\begin{array}{l}\text { Reported } \\
\text { Malaria } \\
\text { case, } \\
\text { (adults) }\end{array}$ & $\begin{array}{l}\text { All-cause } \\
\text { outpatient } \\
\text { consultation, } \\
\text { all ages }\end{array}$ & $\begin{array}{l}\text { All-cause } \\
\text { outpatient } \\
\text { consultation } \\
,<\mathbf{5 .}\end{array}$ & $\begin{array}{l}\text { Predicted } \\
\text { Malaria } \\
\text { Pregnant } \\
\text { women }\end{array}$ \\
\hline $\mathbf{2 0 0 0}$ & $3,349,528$ & $1,303,685$ & $2,045,843$ & $7,000,000$ & $2,591,570$ & $1,227,506$ \\
$\mathbf{2 0 0 1}$ & $3,044,844$ & 856,872 & $2,187,972$ & $6,904,408$ & $1,518,970$ & $1,312,783$ \\
$\mathbf{2 0 0 2}$ & $3,140,893$ & 705,288 & $2,435,605$ & $7,253,794$ & $1,679,257$ & $1,461,363$ \\
$\mathbf{2 0 0 3}$ & $3,552,896$ & $1,421,148$ & $2,131,748$ & $8,129,510$ & $1,900,809$ & $1,279,049$ \\
$\mathbf{2 0 0 4}$ & $3,416,033$ & $1,289,874$ & $2,126,159$ & $7,540,470$ & $1,318,900$ & $1,275,695$ \\
$\mathbf{2 0 0 5}$ & $3,452,969$ & 562,941 & $2,890,028$ & $7,753,845$ & $1,757,833$ & $1,734,017$ \\
$\mathbf{2 0 0 6}$ & $3,511,452$ & 789,952 & $2,721,500$ & $9,114,401$ & $1,712,728$ & $1,632,900$ \\
$\mathbf{2 0 0 7}$ & $3,123,147$ & $1,056,331$ & $2,066,816$ & $9,259,343$ & $3,417,098$ & $1,240,090$ \\
$\mathbf{2 0 0 8}$ & $3,200,147$ & $1,074,267$ & $2,125,880$ & $10,323,853$ & $2,191,381$ & $1,275,528$ \\
\hline
\end{tabular}




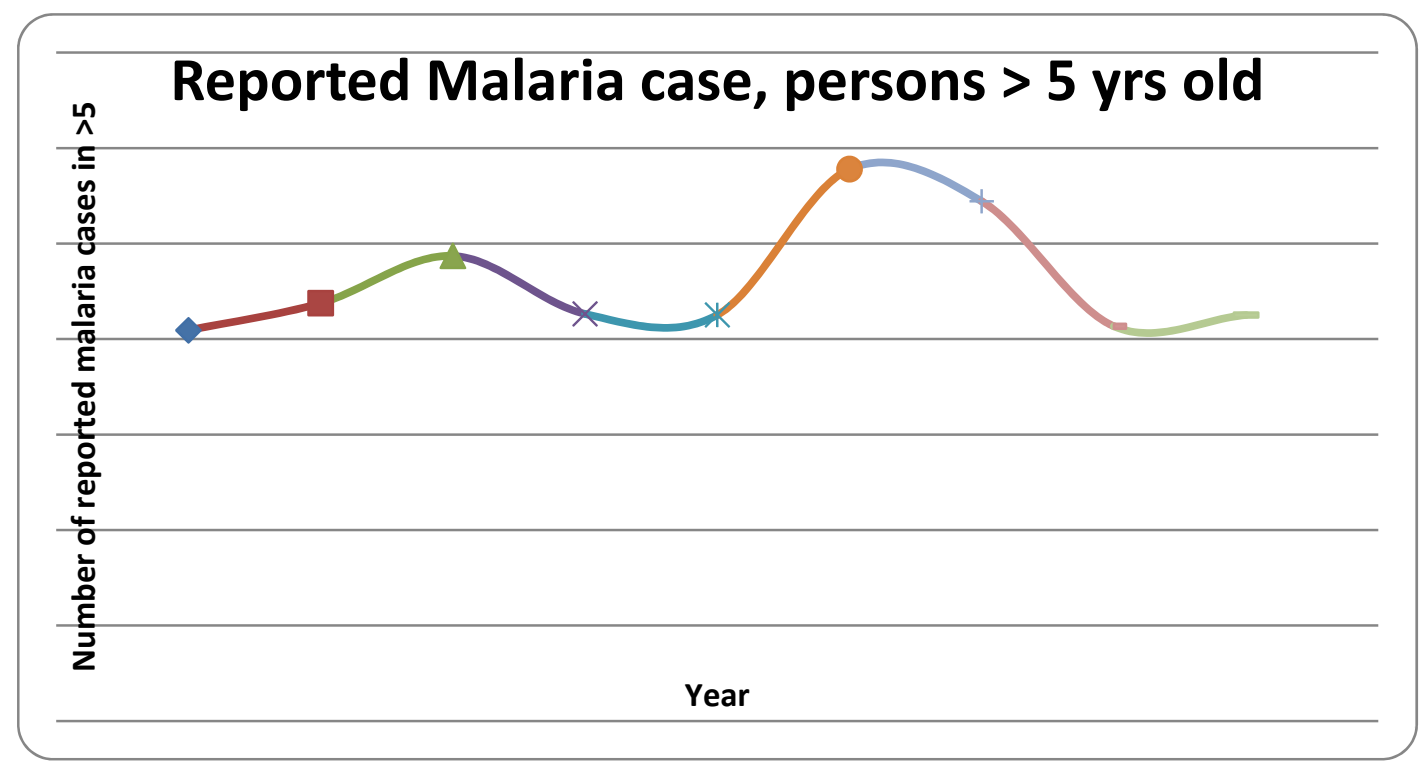

Figure 1. Reported malaria cases in persons older than 5 years old

Table 3 shows the data obtained from the WHO for the number of reported cases or infections. Similar tables for reported admission cases and reported malaria deaths were also obtained.

Figure 1 is a scatter plot of the number of reported cases for persons greater than 5 years old plotted against time. From the scatter plot, we observe that the data is oscillatory. Scatter plots for data for number of infections, admissions and deaths for under 5 year olds, over 5 year olds and pregnant women shows similar oscillatory patterns. Since the scatter plots show a non-linear pattern, a linear regression model cannot be used to project for future values. The graphs are fitted to $6^{\text {th }}$ order polynomials using Microsoft Office Excel's (hereafter referred to as Excel) Data Analysis tool pack. Although the Coefficient of Determination $\left(\mathrm{R}^{2}\right)$ values were extremely high, ranging between $82.47 \%$ and $93.55 \%$, and thus implying a good fit, the model was very poor at projecting the future values and the resulting predicted values were unrealistically high.

Consequently, we rejected regression modeling and rather utilized Time Series analysis, more specifically the Holt's Linear Exponential Smoothing Technique (HLEST). HLEST can be used to forecast k-periods into the future under the assumption that the series $\left\{\mathrm{y}_{\mathrm{t}}\right\}$ is non-seasonal but does display trend. We have already established the existence of a trend (oscillatory).

\subsection{Forecasting with Holt's Linear Exponential Smoothing Techniques (HLEST)}

Malaria cases are seasonal within a year but not between years, hence we can proceed to forecast with the HLEST. HLEST has two smoothing parameters and both must be positive and less than one. A small and $\beta$ provide a detectable and visible smoothing. While a large and provide a fast response to the recent changes in the time series but provides a smaller amount of smoothing. We seek to strike a balance between noticeable smoothing and at the same time place emphasis on more recent observation, we opt for and using these assumed parameters, the following projections are obtained:

Table 4. Projected values for number of malaria infections for different sub-populations

\begin{tabular}{ccccc}
\hline Year & $\begin{array}{c}\text { Reported } \\
\text { malaria cases, } \\
\text { all ages }\end{array}$ & $\begin{array}{c}\text { Reported } \\
\text { cases, }<\mathbf{5}\end{array}$ & $\begin{array}{c}\text { Reported } \\
\text { cases, }>\mathbf{5}\end{array}$ & $\begin{array}{c}\text { Projected cases, } \\
\text { pregnant women }\end{array}$ \\
\hline $\mathbf{2 0 0 9}$ & $3,214,084$ & $1,066,481$ & $2,147,605$ & $1,288,562$ \\
$\mathbf{2 0 1 0}$ & $3,157,645$ & $1,134,853$ & $2,022,794$ & $1,213,676$ \\
$\mathbf{2 0 1 1}$ & $3,101,206$ & $1,203,226$ & $1,897,982$ & $1,138,789$ \\
$\mathbf{2 0 1 2}$ & $3,044,768$ & $1,271,598$ & $1,773,171$ & $1,063,902$ \\
$\mathbf{2 0 1 3}$ & $2,988,329$ & $1,339,970$ & $1,648,360$ & 989,015 \\
\hline
\end{tabular}


Table 5. Projected values for number of malaria admissions for different sub-populations

\begin{tabular}{ccccc}
\hline Year & $\begin{array}{c}\text { All-ages } \\
\text { admission }\end{array}$ & $\begin{array}{c}\text { Under 5 } \\
\text { admissions }\end{array}$ & $\begin{array}{c}\text { Adult } \\
\text { admissions }\end{array}$ & $\begin{array}{c}\text { Pregnant women } \\
\text { admissions }\end{array}$ \\
\hline $\mathbf{2 0 0 9}$ & 252,792 & 76,028 & 176,764 & 106,059 \\
$\mathbf{2 0 1 0}$ & 291,795 & 87,908 & 203,887 & 122,332 \\
$\mathbf{2 0 1 1}$ & 330,797 & 99,788 & 231,009 & 138,605 \\
$\mathbf{2 0 1 2}$ & 369,799 & 111,668 & 258,131 & 154,879 \\
$\mathbf{2 0 1 3}$ & 408,802 & 123,548 & 285,254 & 171,152 \\
\hline
\end{tabular}

Table 6. Projected values for number of malaria deaths for different sub-populations

\begin{tabular}{ccccc}
\hline Year & $\begin{array}{c}\text { all-age reported } \\
\text { deaths }\end{array}$ & $\begin{array}{c}\text { reported } \\
\text { deaths, }<\mathbf{5}\end{array}$ & $\begin{array}{c}\text { eported deaths, } \\
\text { adults }\end{array}$ & $\begin{array}{c}\text { pregnant } \\
\text { women } \\
\text { deaths }\end{array}$ \\
\hline $\mathbf{2 0 0 9}$ & 25,243 & 5,045 & 20,198 & 12,119 \\
$\mathbf{2 0 1 0}$ & 30,167 & 5,184 & 24,983 & 14,990 \\
$\mathbf{2 0 1 1}$ & 35,090 & 5,323 & 29,768 & 17,861 \\
$\mathbf{2 0 1 2}$ & 40,014 & 5,461 & 34,553 & 20,732 \\
$\mathbf{2 0 1 3}$ & 44,937 & 5,600 & 39,338 & 23,603 \\
\hline
\end{tabular}

Tables 4 to 6 show the projected cases for malaria for the years 2009 to 2013 . We now proceed to project Ghana's population in the years 2009, 2010, 2011, 2012 and 2013 using historic population figures we obtained from Ghana Statistical Services.

It can be observed from Figure 2 that the scatter plot has a quadratic pattern. Using Excel's Data analysis tool pack we can obtain the function of the quadratic and use it to predict the population values. The resulting information is presented in Table 8.

Table 7. Historic data on Ghana's population

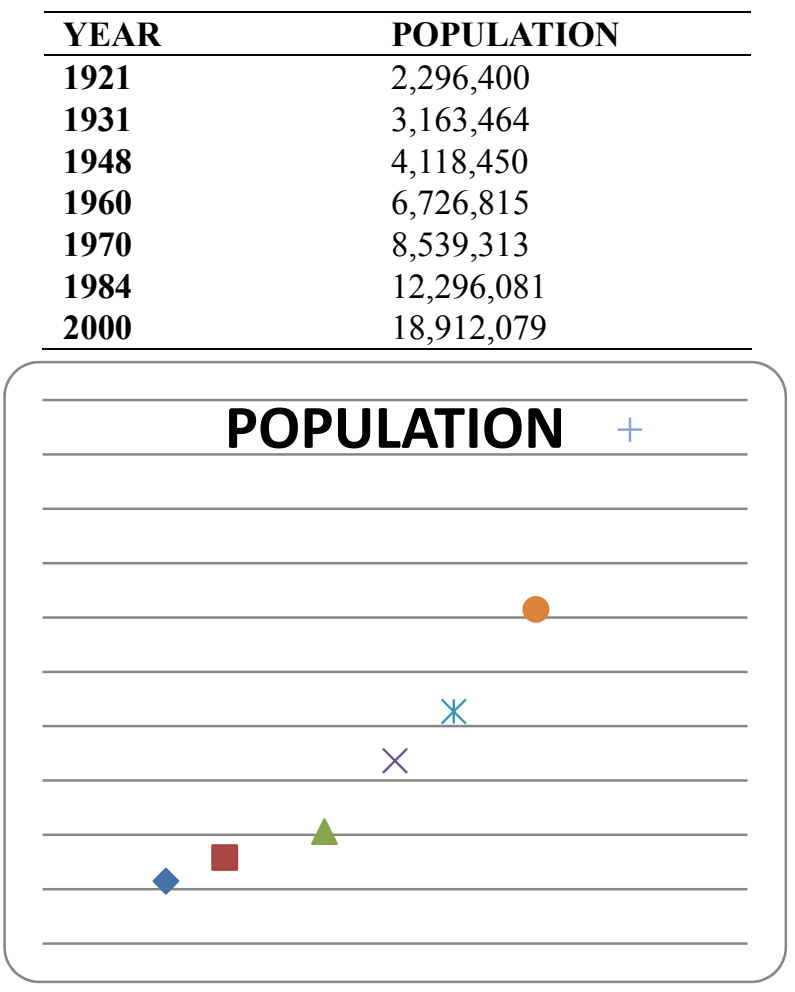

Figure 2. Scatter plot of Ghana's historic population data 
Table 8. Projected population values

\begin{tabular}{cc}
\hline YEAR & Projected population value \\
\hline $\mathbf{2 0 0 9}$ & $22,630,867$ \\
$\mathbf{2 0 1 0}$ & $23,096,740$ \\
$\mathbf{2 0 1 1}$ & $23,567,960$ \\
$\mathbf{2 0 1 2}$ & $24,044,528$ \\
$\mathbf{2 0 1 3}$ & $24,526,442$ \\
\hline
\end{tabular}

Under the assumption that an individual can get at most one episode of malaria in a year, dividing the number of episodes of malaria or the number of malaria admissions or the number of malaria deaths by the total population size gives the proportion of the population who either acquired malaria or were admitted due to malaria or died from malaria. These proportions essentially represent the probabilities of getting infected, admitted or dying from malaria. For example, the number of children (under 5 years old) we projected to get infected with malaria in 2009 was $1,066,481$ and the projected population for 2009 is $22,630,867$. Therefore the proportion of children projected to get malaria in 2009 is $=\frac{1,066,481}{22,630,867}=0.047125062$ and this is equivalent to the probability of a child getting infected with malaria in 2009. Hence using the assumption of only one infection per year, the projected figures for malaria and the projected population figures, we can make a hypothetical morbidity and mortality tables for malaria for the years 2009 to 2013 for each of our subpopulation groups. These are presented in Tables 9 to 11 below.

Table 9. Morbidity and mortality table for under 5 years old

\begin{tabular}{|c|c|c|c|c|c|c|c|}
\hline \multicolumn{8}{|c|}{ MORBIDITY AND MORTALITY TABLE FOR UNDER 5 YEARS OLD } \\
\hline \multirow[t]{2}{*}{ YEAR } & \multirow[t]{2}{*}{ Population } & \multirow{2}{*}{$\begin{array}{l}\text { Expected } \\
\text { number of } \\
\text { cases }\end{array}$} & \multirow{2}{*}{$\begin{array}{l}\text { Expected } \\
\text { number of } \\
\text { admission }\end{array}$} & \multirow{2}{*}{$\begin{array}{l}\text { Expected } \\
\text { number of } \\
\text { deaths }\end{array}$} & \multicolumn{3}{|c|}{ Probability of } \\
\hline & & & & & $\begin{array}{l}\text { getting } \\
\text { infected }\end{array}$ & $\begin{array}{l}\text { getting } \\
\text { admitted }\end{array}$ & dying \\
\hline 2009 & $22,630,867$ & $1,066,481$ & 76,028 & 5,045 & 0.0471251 & 0.0033595 & 0.0002229 \\
\hline 2010 & $23,096,740$ & $1,134,853$ & 87,908 & 5,184 & 0.0491348 & 0.0038061 & 0.0002244 \\
\hline 2011 & $23,567,960$ & $1,203,226$ & 99,788 & 5,323 & 0.0510535 & 0.0042341 & 0.0002258 \\
\hline 2012 & $24,044,528$ & $1,271,598$ & 111,668 & 5,461 & 0.0528851 & 0.0046442 & 0.0002271 \\
\hline 2013 & $24,526,442$ & $1,339,970$ & 123,548 & 5,600 & 0.0546337 & 0.0050373 & 0.0002283 \\
\hline
\end{tabular}

Table 10. Morbidity and mortality table for persons over 5 years old (excluding pregnant women)

\begin{tabular}{|c|c|c|c|c|c|c|c|}
\hline \multicolumn{8}{|c|}{ MORBIDITY AND MORTALITY TABLE FOR ADULTS (EXCLUDING PREGNANT WOMEN) } \\
\hline \multirow[t]{2}{*}{ YEAR } & \multirow[t]{2}{*}{ Population } & \multirow{2}{*}{$\begin{array}{l}\text { Expected } \\
\text { number of } \\
\text { cases }\end{array}$} & \multirow{2}{*}{$\begin{array}{l}\text { Expected } \\
\text { number of } \\
\text { admission }\end{array}$} & \multirow{2}{*}{$\begin{array}{l}\text { Expected } \\
\text { number of } \\
\text { deaths }\end{array}$} & \multicolumn{3}{|c|}{ Probability of } \\
\hline & & & & & $\begin{array}{l}\text { getting } \\
\text { infected }\end{array}$ & $\begin{array}{l}\text { getting } \\
\text { admitted }\end{array}$ & dying \\
\hline 2009 & $22,630,867$ & 859,042 & 70,706 & 8,079 & 0.0379589 & 0.0031243 & 0.0003570 \\
\hline 2010 & $23,096,740$ & 809,118 & 81,555 & 9,993 & 0.0350317 & 0.0035310 & 0.0004327 \\
\hline 2011 & $23,567,960$ & 759,194 & 92,404 & 11,907 & 0.0322130 & 0.0039207 & 0.0005052 \\
\hline 2012 & $24,044,528$ & 709,269 & 103,253 & 13,821 & 0.0294982 & 0.0042942 & 0.0005748 \\
\hline 2013 & $24,526,442$ & 659,345 & 114,101 & 15,735 & 0.0268830 & 0.0046522 & 0.0006416 \\
\hline
\end{tabular}

Table 11. Morbidity and mortality table for pregnant women

\begin{tabular}{|c|c|c|c|c|c|c|c|}
\hline \multicolumn{8}{|c|}{ MORBIDITY AND MORTALITY TABLE FOR PREGNANT WOMEN } \\
\hline \multirow[t]{2}{*}{ YEAR } & \multirow[t]{2}{*}{ Population } & \multirow{2}{*}{$\begin{array}{l}\text { Expected } \\
\text { number of } \\
\text { cases }\end{array}$} & \multirow{2}{*}{$\begin{array}{l}\text { Expected } \\
\text { number of } \\
\text { admission }\end{array}$} & \multirow{2}{*}{$\begin{array}{l}\text { Expected } \\
\text { number of } \\
\text { deaths }\end{array}$} & \multicolumn{3}{|c|}{ Probability of } \\
\hline & & & & & $\begin{array}{l}\text { getting } \\
\text { infected }\end{array}$ & $\begin{array}{l}\text { getting } \\
\text { admitted }\end{array}$ & dying \\
\hline 2009 & $22,630,867$ & $1,288,562$ & 106,059 & 12,119 & 0.0569383 & 0.0046865 & 0.0005355 \\
\hline 2010 & $23,096,740$ & $1,213,676$ & 122,332 & 14,990 & 0.0525475 & 0.0052965 & 0.0006490 \\
\hline 2011 & $23,567,960$ & $1,138,789$ & 138,605 & 17,861 & 0.0483194 & 0.0058811 & 0.0007578 \\
\hline 2012 & $24,044,528$ & $1,063,902$ & 154,879 & 20,732 & 0.0442472 & 0.0064413 & 0.0008622 \\
\hline 2013 & $24,526,442$ & 989,015 & 171,152 & 23,603 & 0.0403245 & 0.0069783 & 0.0009623 \\
\hline
\end{tabular}


The final component needed before we can proceed to construct the premium model is the life table of Ghana, which gives us the probabilities of surviving and dying at different ages. Incidentally, there exist no unique life tables pertaining to the Ghanaian population. Most life tables used in Ghana for teaching and practice are the South African life tables loaded for special Ghanaian mortality factors and the North American life tables.

Since we could not obtain a South African life table, we opt for a North American life table i.e. the Illustrative Life Table (ILT) of the Society of Actuaries (SoA). The mortality probabilities in the ILT will be loaded for extra mortality factors in Ghana. The overall life expectancy at birth of a person born in the United States is 78.2 years where as the overall life expectation at birth of a person born in Ghana is 60.0 years. This implies that the complete expectation of life for a Ghanaian is lesser than that of a North American by a factor of $\frac{60.0}{78.2}=0.7672$ and thus, on average, a Ghanaian has $76.72 \%$ of the survival probability of a North American.

However, since we aim to load for extra mortality, the inverse of the above ratio and the loading factor, which is given by $(0.7673)^{-1}=1.30333$ is used. We now assume that the $\mathrm{q}_{\mathrm{x}}$-the probability of a person age $\mathrm{x}$ dying at $x+1$ year - values for the Ghanaian population is greater than that of an American population by the loading factor at all ages. An excerpt of the resulting life table is shown below.

Table 12. Excerpt of the adjusted ILT used as Ghanaian life table for ages $0-35$

\begin{tabular}{ll}
\hline $\mathrm{X}$ & age of person \\
$\mathrm{q}(\mathrm{x})$ & probability that a person aged $\mathrm{x}$ dies before age $\mathrm{x}+1$ \\
$\mathrm{P}(\mathrm{x})$ & probability that a person aged $\mathrm{x}$ survives to age $\mathrm{x}+1$ \\
loading factor & 1.303333333 \\
\hline
\end{tabular}

\begin{tabular}{|c|c|c|c|c|c|}
\hline \multirow[b]{2}{*}{$\mathbf{X}$} & \multicolumn{2}{|c|}{ Illustrative life Table } & \multicolumn{3}{|c|}{ Adjusted ILT or Ghanaian Life Table } \\
\hline & $1000 q(x)$ & $q(x)$ & $1000 q(x)$ & $q(x)$ & $\mathbf{p}(\mathbf{x})$ \\
\hline 0 & 20.42 & 0.02042 & 26.61407 & 0.02661 & 0.973386 \\
\hline 5 & 0.98 & 0.00098 & 1.27727 & 0.00128 & 0.998723 \\
\hline 10 & 0.85 & 0.00085 & 1.10783 & 0.00111 & 0.998892 \\
\hline 15 & 0.91 & 0.00091 & 1.18603 & 0.00119 & 0.998814 \\
\hline 20 & 1.03 & 0.00103 & 1.34243 & 0.00134 & 0.998658 \\
\hline 21 & 1.06 & 0.00106 & 1.38153 & 0.00138 & 0.998618 \\
\hline 22 & 1.10 & 0.00110 & 1.43367 & 0.00143 & 0.998566 \\
\hline 23 & 1.13 & 0.00113 & 1.47277 & 0.00147 & 0.998527 \\
\hline 24 & 1.18 & 0.00118 & 1.53793 & 0.00154 & 0.998462 \\
\hline 25 & 1.22 & 0.00122 & 1.59007 & 0.00159 & 0.998410 \\
\hline 26 & 1.27 & 0.00127 & 1.65523 & 0.00166 & 0.998345 \\
\hline 27 & 1.33 & 0.00133 & 1.73343 & 0.00173 & 0.998267 \\
\hline 28 & 1.39 & 0.00139 & 1.81163 & 0.00181 & 0.998188 \\
\hline 29 & 1.46 & 0.00146 & 1.90287 & 0.00190 & 0.998097 \\
\hline 30 & 1.53 & 0.00153 & 1.99410 & 0.00199 & 0.998006 \\
\hline 31 & 1.61 & 0.00161 & 2.09837 & 0.00210 & 0.997902 \\
\hline 32 & 1.70 & 0.00170 & 2.21567 & 0.00222 & 0.997784 \\
\hline 33 & 1.79 & 0.00179 & 2.33297 & 0.00233 & 0.997667 \\
\hline 34 & 1.90 & 0.00190 & 2.47633 & 0.00248 & 0.997524 \\
\hline 35 & 2.01 & 0.00201 & 2.61970 & 0.00262 & 0.997380 \\
\hline
\end{tabular}


The International Actuarial Notations (IAN) for survival and mortality rates shall be adopted, therefore $\mathrm{q}(\mathrm{x})=\mathrm{q}_{\mathrm{x}}$ and $\mathrm{p}(\mathrm{x})=\mathrm{p}_{\mathrm{x}}$ in our calculations. Furthermore, since there are no survival or mortality probabilities for ages 1 to 4 , we assume that $\mathrm{q}(1)=\mathrm{q}(2)=\mathrm{q}(3)=\mathrm{q}(4)$.

\subsection{Calculating Premiums}

The Equivalence Principle shall be employed for premium calculation. This principle states that the expected present value or the Actuarial Present Value (APV) of income or inflow must equal the expected present value or Actuarial Present Value (APV) of the outflows.

The following assumptions are made:

a) Constant premiums are paid at the beginning of the year.

b) (x) denotes the current age of the policy holder.

c) Benefits are paid at the end of year of the contingency i.e. malaria infection, admission or death.

d) Independence assumption. This is explained as the probability of getting infected, admitted or dying in one year is independent of the probability of getting infected in other years or the following years.

e) $T_{j}(x)$ is future-time of infection, admission or death for person aged $x$. This is further explained as time till infection, admission or death of the person age $\mathrm{x} . \mathrm{j}=1$ for infection, 2 for admission and 3 for death. We shall use $\mathrm{T}$ for simplicity.

f) $i$ is the constant rate of interest over the period of coverage. This is the interest rate that will be earned by the scheme when it invests the premium proceeds. In calculating the pure premium we will adopt the average 1-year Treasury bill rate for 2010. We adopt the Treasury bill rate because it is the highest risk - free rate for investment in any economy. The current average rate of interest for Ghana is $14.3 \%$.

With these assumptions, the actuarial present value of premiums can be calculated as follows:

$$
\begin{gathered}
A P V(\text { premiums })=\sum_{t=0}^{2} p(t)\left(\frac{1-v^{t}}{d}\right) \cdot f(t) \\
=\sum_{t=0}^{2} p(t) \cdot \ddot{a}_{t} \cdot f(t) .
\end{gathered}
$$

Where

$\mathrm{P}(\mathrm{t})$ : the premium amount paid at time $\mathrm{t}$, where the summation runs from time 0 (policy issue) to time 2 .

$\mathrm{V}^{\mathrm{t}}$ : the discounting factor to discount a payment from time $\mathrm{t}$ to time 0 . Mathematically, this is

$$
\mathrm{v}^{\mathrm{t}}=\left(\frac{1}{1+i}\right)^{t}=\left(\frac{1}{1.143}\right)^{t}=(0.874890639)^{t}
$$

$d$ : the discount rate. This is the value of the interest rate at the beginning of the time period (year).

$\ddot{a}_{t}$ : the annuity - due notation. It is the present value of the random variable for annual payments of 1 at the beginning of the year for' $\mathbf{t}$ ' years. 
$f(t)$ the probability function of time till infection or probability of the infection.

Using summation by parts on equation 3.4 and factoring in the constant premium assumption reduces it to

$$
=P \sum_{t=0}^{2} v^{t} \mathrm{p}_{\mathrm{x}}=\mathrm{P}\left(1+\mathrm{vp}_{\mathrm{x}}+\mathrm{v}^{2}{ }_{2} \mathrm{p}_{\mathrm{x}}\right)=\mathrm{P}\left(1+\mathrm{v} \mathrm{p}_{\mathrm{x}}+\mathrm{v}^{2} \mathrm{p}_{\mathrm{x}} \cdot \mathrm{p}_{\mathrm{x}+1}\right)
$$

The actuarial present value of benefits can similarly be calculated for the general case where the benefit of the contingency is some specified amount GHф K. Using the same assumptions as for the calculation of the premium, we get:

$$
\operatorname{APV}(\text { benefits })=K\left(\mathrm{vq}_{\mathrm{x}}+\mathrm{v}^{2} \mathrm{p}_{\mathrm{x}} \mathrm{q}_{\mathrm{x}+1}+\mathrm{v}^{3} \mathrm{p}_{\mathrm{x}} \mathrm{p}_{\mathrm{x}+1} \mathrm{q}_{\mathrm{x}+2}\right)
$$

Under the equivalence principle we have

$$
\begin{gathered}
\mathrm{APV}(\text { premiums })=\mathrm{APV} \text { (benefits) } \\
\mathrm{P}\left(1+\mathrm{vp}_{\mathrm{x}}+\mathrm{v}^{2} \mathrm{p}_{\mathrm{x} \cdot} \cdot \mathrm{p}_{\mathrm{x}+1}\right)=\mathrm{K}\left(\mathrm{vq}_{\mathrm{x}}+\mathrm{v}^{2} \mathrm{p}_{\mathrm{x}} \cdot \mathrm{q}_{\mathrm{x}+1}+\mathrm{v}^{3} \mathrm{p}_{\mathrm{x}} \cdot \mathrm{p}_{\mathrm{x}+1} \mathrm{q}_{\mathrm{x}+2}\right)
\end{gathered}
$$

where $\mathrm{K}=23,84$ and $\mathrm{D}$

And making $\mathrm{P}$ the subject of equation 2.4.7 we get

$$
P=\frac{K\left(v q_{x}+v^{2} p_{x} \cdot q_{x+1}+v^{3} p_{x} \cdot p_{x+1} \cdot q_{x+2}\right)}{1+v p_{x}+v^{2} p_{x} \cdot p_{x+1}}
$$

Equation (2.4.8) is the premium formula and it forms the foundation of the health scheme. Given a specific benefit amount, the corresponding annual constant premium for a 3-year term health insurance cover can be ascertained.

\section{Discussion}

\section{Illustration}

As an example, we calculate the three-year term insurance premium for a non-pregnant policyholder aged 23 years who buys the policy at the beginning of 2011 using equation (2.4.8) and the data given in Table 2. For this particular person, the equation becomes:

$$
P=\frac{23 \times\left(v q_{23}+v^{2} p_{23} \cdot q_{24}+v^{3} p_{23} \cdot p_{24} \cdot q_{25}\right)}{1+v p_{23}+v^{2} p_{23} \cdot p_{24}}
$$

Using values from Table 10 and 12, we get

$$
\mathrm{P}=0.599065
$$

Hence the premium for the first cover would be GHф0.60. To obtain the premium for the second cover, we note that the cost of the second cover is that of the first cover plus an additional amount for the extra benefits from the second cover. Thus we get the premium for the extra cost associated with the second cover and add this amount to the premium of the first cover to get the total premium for the second cover. Denoting the extra cost by e, we get

$$
e=\frac{84 \times\left(v q_{23}+v^{2} p_{23} \cdot q_{24}+v^{3} p_{23} \cdot p_{24} \cdot q_{25}\right)}{1+v p_{23}+v^{2} p_{23} \cdot p_{24}}=0.3127971
$$

Hence the total premium for the second cover is $\mathrm{P}_{2}=\mathrm{P}+\mathrm{e}=0.599+0.3127=0.911862$. We obtain the premium for the final cover in a similar manner and summarize the results in the following table.

Table 13. Premiums for different covers for 23 year old female (not pregnant)

\begin{tabular}{lcc}
\hline Premium & Value & Amount in $\mathrm{GH} \phi$ \\
\hline $\mathrm{P}_{1}$ & 0.59906 & 0.60 \\
$\mathrm{P}_{2}$ & 0.91185 & 0.91 \\
$\mathrm{P}_{3}$ & 1.32516 & 1.33 \\
\hline
\end{tabular}

\subsection{Cost-benefit Analysis}

The above premiums seem to be unrealistically small. $\mathrm{P}_{3}$ for instance, implies that for a fee of GH $\not 1.33$, a person aged 23 yrs old can get a comprehensive malaria insurance cover. We obtained our morbidity and mortality tables using the population of Ghana and therefore implicit in those calculations are the assumption that all Ghanaians shall participate 
in the insurance. Let's perform a cost benefit analysis to see if the premiums collect shall be enough to cover the resulting costs.

We shall proceed under the assumption that the scheme has homogenous cohort membership with respect to age, that is, all members of the scheme are 23 years old. This assumption, though simplistic, would make our analysis easier.

Table 14. Cost-Benefit analysis for 23 year old (non-pregnant)

\begin{tabular}{lcccc}
\hline & INFECTION & ADMISSION & DEATH & \\
Premium & 0.60 & 0.31 & 0.41 & \\
Number (1) & $23,567,960$ & $23,567,960$ & $23,567,960$ & \\
Cost & 23 & 84 & 800 & \\
Number (2) & 759,194 & 92,404 & 11,907 & Grand total \\
Total premium & $16,137,711$ & $8,426,183$ & $11,133,364$ & $35,697,258$ \\
Total Cost & $17,461,462$ & $7,761,936$ & $9,525,600$ & $34,748,998$ \\
\hline
\end{tabular}

From the table above, i.e. Table 14, the premium and cost represents the amount for an individual where as the 'totals' represents that of the lives in cohort. Number (1) represents the number of people who under the scheme obligated to pay premiums for a year and number (2) represent the predicted number of claims for a year.

Also, we assumed that premiums are paid at the beginning of the year where as claims are paid at the end of the year. We accumulated premiums in our cost-benefit calculations to account for the time value of money. We observe from Table 14 that although the premiums were small, thus making the number of people required to make premiums far out-number those predicted to make claims and thus the aggregate benefit is enough to cover the aggregate cost and thus grand total premium outweighs the grand total cost. This is because of the simplification assumption of homogeneity we made.

If the actual predicted numbers for all ages were used, the grand total for premium would have equaled the grand total for cost. This is implicit in the equivalence principle. For ease of comparison, we do a cost-benefit analysis for a 23 year old pregnant woman and another for a 1 new born baby. The homogeneity assumption applies in these scenarios as well.

Table 15. Cost-Benefit analysis for 23 year old (pregnant)

\begin{tabular}{lcccl}
\hline & Infection & Admission & Death & \\
Premium & 0.90 & 0.47 & 0.60 & \\
Number & $23,567,960$ & $23,567,960$ & $23,567,960$ & \\
Cost & 23 & 84 & 800 & \\
Number & $1,138,789$ & 138,605 & 17,861 & Grand Total \\
Total premium & $24,206,527$ & $12,638,975$ & $16,055,942$ & $52,901,444$ \\
Total Cost & $26,192,147$ & $11,642,820$ & $14,288,800$ & $52,123,767$ \\
\hline
\end{tabular}

Table 16. Cost-Benefit analysis for a newborn baby

\begin{tabular}{lcccc}
\hline & Infection & Admission & Death & \\
Premium & 1.06 & 0.35 & 0.16 & \\
Number & $23,567,960$ & $23,567,960$ & $23,567,960$ & \\
Cost & 23 & 84 & 800 & \\
Number & $1,203,226$ & 99,788 & 5,323 & Grand Total \\
Total premium & $28,556,287$ & $9,444,785$ & $4,278,867$ & $42,279,943$ \\
Total Cost & $27,674,198$ & $8,382,192$ & $4,258,400$ & $40,314,790$ \\
\hline
\end{tabular}

\section{Conclusion and Recommendations}

\subsection{Conclusion}

From Tables 15 and 16, it is observed that the amount of claims and premiums paid are highest for the pregnant women and lowest for non-pregnant adults. This is in accordance with normality as the pregnant and children 
subpopulations have higher probabilities of getting infected, admitted and dying from malaria due to lower immunity in those subpopulations. We also notice that in all three cases the grand premium amount is higher than the grand claim amount. This is as a result of the homogeneity assumption we made. Had the actual predicted numbers been used for all ages rather than assuming a single age for all members, the grand premium would have been equal to the grand cost, as implied by the Equivalence principle.

The objectives of this study were to estimate the financial cost associated with malaria, estimate morbidity and mortality tables for malaria for the Ghanaian population and finally to derive a premium formula to calculate premiums for the malaria scheme. The results of these objectives are presented in the study as follows:

\begin{tabular}{ll}
\hline Objective & \\
\hline Estimating financial cost of malaria & Table 1, Table 2 \\
Estimating morbidity and mortality tables & Table 9, Table 10, Table 11, Table 12 \\
Premium formula and calculated premiums & Equation (1), Table 13, Table 14, Table 15, Table 16 \\
\hline
\end{tabular}

4.2 Recommendations

An examination of our morbidity and mortality tables show that pregnant women and children are the most vulnerable to malaria. This is confirmed by Table 17 which shows the average morbidity and mortality probabilities.

Table 17. Average probabilities of infections, admissions and deaths over projected period

\begin{tabular}{|c|c|c|c|c|c|}
\hline \multicolumn{6}{|c|}{ AVERAGE PROBABILITIES OVER PROJECTED PERIOD (2009-2013) } \\
\hline \multicolumn{2}{|c|}{ INFECTIONS } & \multicolumn{2}{|c|}{ ADMISSIONS } & \multicolumn{2}{|c|}{ DEATHS } \\
\hline Children & 0.050966 & Pregnant women & 0.043920 & Pregnant women & 0.000753 \\
\hline Pregnant women & 0.048475 & children & 0.041571 & Children & 0.000226 \\
\hline Adults & 0.032317 & Adults & 0.039269 & Adults & 0.000502 \\
\hline
\end{tabular}

In actuarial literature, adults (excluding pregnant women) would be classified as "good risk" where as children and pregnant women would be classified as "bad risks". In any insurance scheme it is an accepted principle that the standard group or those regarded as good risk and those insurable at the standard or preferred rates, should be broad enough to encompass the greatest percentage of applicants. Since this is to be a national scheme and people cannot be rejected or turned away, this principle of selection of risk cannot be applied very well. Pregnant women and children, though bad risks, cannot be turned away. Fortunately, adults (non-pregnant) form the largest subpopulation in Ghana and this, inevitably, is to the advantage of the national scheme.

Since we would ultimately like to integrate our scheme into the National Health Insurance Scheme (NHIS) and the NHIS currently charges a flat annual national rate, we would need to determine flat rates for the malaria infection cover and malaria admission cover. In order to do this, we would require the average cost associated with a malaria infection and also the average cost of admission and this has to be a national average or, at the very least, an average for the districts currently covered under the NHIS. We would then consider factors, such as inflation in costs, which might affect the cost of diagnosis and treatment over the three year period which our insurance is to cover. We would then use these factors to project the cost of malaria over these three years and finally find the mean of these costs. This would represent our cost of infection and cost of admission which we can insert into equation (2.4.8) to obtain flat premiums for these two covers. Assume this average benefit amount is $\mathrm{GH} \phi 50$. This implies that for some cases, the cost would be less and the scheme would make a profit and other cases, the cost would be more and the scheme would make a loss but on average the scheme would break-even.

Therefore to incorporate our Malaria scheme into the NHIS would require some changes to the Malaria scheme model and the most important of these changes are:

a. Determine the national average cost of malaria infection per episode. This can be done by sampling some health institutions throughout the country. This sampling has to be random and more importantly representative of the whole country.

b. Determine the national average cost of malaria admission per episode and follow the same principles as those of the cost of infection.

c. Insert the resulting average costs into equation 2.4 .8 to obtain the flat premium rates for these two covers. 
d. The resulting average costs are just nominal amounts for that particular year. We must factor in the effects of inflations. Medical inflation in Ghana is $9 \%$ on average. We should consequently inflate these costs over the three year period and use the nominal costs in our calculations.

The assumption that benefit payment are made at the end of the year, though mathematically convenient, is extremely unrealistic. In reality, benefits are paid at the moment of the contingency. Conveniently, the remedy to this is very simple: multiple all premium amount by a constant factor $\mu=\hat{i} / \delta$, where $i$ is the constant annual effective interest rate and $\delta$ is the constant force of interest. This means that premiums are discrete and paid at the beginning where are benefits are continuous. We also recommend that the model be updated as frequently as possible to keep up with changing factors. One such factor is interest rate.

In our model we settled on $14.3 \%$ and any future changes in interest rates should duly be reflected in the model. Another factor that needs to be updated is the survival rates factor. For our model, we chose the Illustrative Life Table and loaded it to adopt it for Ghana. Ideally, we should have used a genuinely constructed Ghanaian Life table but life tables require a lot of money, time, effort and a great deal of technical skill to construct. We would not recommend updating it too frequently but rather using the loading-factor technique to update the model every other year and perhaps constructing a life table every 10 to 15 years, which will coincide with national censuses.

Finally, we would recommend that a deductible be included in the scheme to cater for administrative cost. The premium we calculated was a pure premium and hence independent of any other expenses except cost of benefit. In medical insurance, most of these other expenses can be classified under administrative cost. We therefore recommend that a study be done to ascertain the average administrative cost in the country and this resulting amount be set as the deductible amount so as to militate against small claims which tend to negatively affect insurance schemes.

\section{References}

Accorsi, S., Adams, I., \& Darko, D. (2004 October). Malaria: A Burden Explored. Bulletin of Health Information, $1(1)$.

Akazili, J. (2002). Costs to households of seeking malaria care in the Kassena-Nankana District of Northern Ghana. In Third MIM Pan-African Conference on Malaria, Arusha, Tanzania, 17-22, November 2002. Bethesda, MD, Multilateral Initiative on Malaria.

Ankomah Asante, F. A., \& Asenso-Okyere K. (2003 November). Economic Burden of Malaria in Ghana. A Technical Report Submitted to the World Health Organisation (WHO), African Regional Office (AFRO).

Bowers, N. L., Gerber, H. U., \& Hickman, J. C. (1997). Actuarial Mathematics (2nd ed.). Society of Actuaries publications, USA

Centre for Health Information Management, Ghana Health Service, 2003.

Makalo, Sulayman. (2008, November 22). Malaria Cripples Ghana's Health Budget. Afrol News.

Merphy Morgan. (2010). President Malaria Initiative e-newsletter, April issue.

Ministry of Health. (1991). Malaria Action Plan: 1993-1997. MoH, Accra.WHO World Malaria Report, 2009. Country Profile - Ghana. Retrieved from http/www.who.int/malaria/wmr2009/

Ministry of Health. (2008). Malaria Action Plan. MoH, Accra.

WHO/UNICEF. (2003). Africa Malaria Report. WHO/CDS/MAL/2003.1093. 2003. 